\title{
GEOSUL
}

\section{GEOGRAFIA E EDUCAÇÃO: UMA DISCUSSÃO EPISTEMOLÓGICA}

\author{
Victória Sabbado Menezes ${ }^{1}$ \\ Nestor André Kaercher ${ }^{2}$
}

\begin{abstract}
Resumo: A pesquisa em ensino de Geografia escolar no Brasil tem se fortalecido nas últimas décadas e revelado a importância de repensar as práticas educativas desenvolvidas a fim de que se tornem significativas, de fato, para os sujeitos da aprendizagem. Nesse sentido, partese da perspectiva que a discussão meramente metodológica não é suficiente. É necessário ir às raízes do fazer docente. Assim, o presente artigo apresenta uma reflexão teórica concernente à epistemologia do professor pautando-se fundamentalmente em Fernando Becker, o qual distingue os modelos pedagógicos e epistemológicos da Educação. Considera-se que, para além de uma crítica ao modelo pedagógico adotado pelo professor, é essencial uma crítica epistemológica. Portanto, repensar a prática de ensino em Geografia exige uma discussão epistemológica e pressupõe a formação de professores pesquisadores e reflexivos.
\end{abstract}

Palavras-chave: Geografia; Educação; Epistemologia

\section{GEOGRAPHY AND EDUCATION: AN EPISTEMOLOGICAL DISCUSSION}

\begin{abstract}
A research on Geography teaching at schools in Brazil has strengthened in recent decades and revealed the importance of rethinking the educational practices developed so that they become significant, in fact, to the learning subjects. In this sense, it starts from the perspective that merely methodological discussion is not sufficient. It is necessary to consider the stakes of teaching. Thus, this paper presents a theoretical reflection concerning the teacher's epistemology, and it focuses mainly on Fernando Becker, who distinguishes the pedagogical and epistemological models of Education. It is considered that, in addition to a review of the pedagogical model adopted by the teacher, it is essential an epistemological criticism. Therefore, rethinking teaching practices in Geography requires an epistemological discussion and presupposes training for reflective and research teachers.
\end{abstract}

Key-words: Geography; Education; Epistemology

\section{GEOGRAFÍA Y EDUCACIÓN: UNA DISCUSIÓN EPISTEMOLÓGICA}

Resumen: La investigación en enseñanza de Geografía escolar en Brasil se ha fortalecido en las últimas décadas y ha revelado la importancia de que se repiensen las prácticas educativas desarrolladas a fin de que se vuelvan efectivamente significativas para los sujetos del aprendizaje. De esa manera, se parte de la perspectiva de que la discusión meramente metodológica no es suficiente. Se vuelve necesario ir a las raíces del hacer docente. Así, este artículo presenta una reflexión teórica concerniente a la epistemología del profesor, la cual se pauta fundamentalmente en Fernando Becker, quien distingue los modelos pedagógicos y epistemológicos de la Educación. Se considera que, más allá de una crítica al modelo pedagógico adoptado por el profesor, resulta esencial que se haga una crítica epistemológica.

\footnotetext{
${ }^{1}$ Mestre em Geografia pelo Programa de Pós-Graduação em Geografia da UFRGS. Email: victoriasabbado@gmail.com

${ }^{2}$ Professor Doutor do Programa de Pós-Graduação em Geografia da UFRGS. Email: nestorandrek@gmail.com
} 
Por lo tanto, repensar la práctica de enseñanza en Geografía exige una discusión epistemológica y presupone la formación de profesores investigadores y reflexivos.

Palabras clave: Geografía; Educación; Epistemología

\section{INTRODUÇÃO}

A contemporaneidade tem revelado um mundo cada vez mais incerto, dinâmico e mutável. Nos mais diversos contextos, seja político, econômico, social, cultural e ambiental, as mudanças ocorrem constantemente e, muitas vezes, de forma rápida. O turbilhão de informações que recebemos diariamente, o surgimento de novas tecnologias e as novas demandas da sociedade fazem com que os sujeitos sejam surpreendidos pelo ritmo acelerado da vida cotidiana. Dessa maneira, o questionamento e a reflexão constante são condição sine qua non para que se possa interpretar e lidar com a realidade complexa que se apresenta hoje. Diante disso, como o professor e a escola se colocam nesse contexto?

Deve-se ressaltar que, muitas vezes, os professores são orientados durante a formação inicial para trabalhar sob uma determinada lógica e, anos depois, quando assumem uma sala de aula são impactados com uma outra realidade. Isso porque aquelas orientações recebidas na licenciatura não são mais aplicáveis ao contexto que ora se apresenta ao professor, tendo em vista as rápidas mudanças sociais. Consequentemente, o professor tem a necessidade de desenvolver outras práticas, porém, na maioria dos casos, o caminho trilhado corresponde à adoção de novas técnicas e metodologias, havendo uma modificação apenas instrumental.

Não se tem a pretensão de desvalorizar a atitude do docente em relação ao emprego de diversas metodologias. Ao contrário, defende-se a ideia de que a utilização de diferentes estratégias metodológicas tende a desacomodar os estudantes, de forma que a aula não se torna monótona e previsível. No entanto, o ponto que se pretende chegar ultrapassa a questão metodológica e refere-se à postura epistemológica do professor. Eis aqui o eixo central de análise deste artigo, qual seja: a concepção pedagógica e epistemológica de Educação do professor de Geografia.

\section{TODA EPISTEMOLOGIA REMETE A UMA PEDAGOGIA}

Veiga-Neto (2012), recorrendo às metáforas bachelardianas, considera que aqueles que trabalham no campo da Educação devem interessar-se por toda a casa, isto é, pelo porão, onde estão enraizados os pensamentos, pelo piso intermediário, onde são desenvolvidas as práticas pedagógicas e pelo sótão, onde se encontram os sonhos e as utopias. O autor ressalta 
que uma boa parcela dos docentes tem se limitado ao piso intermediário e, no máximo, também ao sótão. Sendo assim:

Poucos descem aos fundamentos nos quais se enraízam suas opções epistemológicas e, consequentemente, poucos conhecem o subsolo em que se alimentam suas convicções acerca da salvação por toda obra da educação. Não se trata, é claro, de dizer que não são feitas opções ou que não há convicções (sociais, políticas, pedagógicas, metodológicas, éticas etc.). Afirmar isso seria um engano crasso! O que me parece fazer falta é saber de onde vieram e como se engendraram tais opções e convicções. O que falta para muitos de nós é descer aos porões. A imensa maioria tão somente toma de empréstimo tais opções e convicções, assumindo-as como verdades naturais e, desse modo, não problematizáveis. (VEIGA-NETO, 2012, p. 276)

Conhecer nossos porões é imprescindível para que se desenvolvam práticas pedagógicas coerentes com o discurso que se expressa. O papel do professor na atualidade será exercido plenamente se o mesmo estiver apoiado em uma epistemologia definida. A prática pedagógica não terá sentido nem para o educador nem para o educando se não estiver assentada em concepções claras do docente. Logo, reitera-se que não basta uma mudança metodológica, é preciso uma mudança epistemológica, "tanto da visão de Geografia (trocar informações soltas e estanques por alguma visão mais articulada à vida dos alunos), quanto de outra visão de Educação/Pedagogia (para que ensinar o que eu ensino?) [...]” (KAERCHER, 2014, p. 117).

As concepções epistemológicas apresentadas pelo professor são provenientes da sua afinidade com determinada corrente teórica tanto da Geografia quanto da Educação. De acordo com seus valores, sua visão de mundo, seus ideais, sua postura política se assentará em determinada concepção epistemológica. Desse modo, todo professor está apoiado em uma epistemologia, mesmo que de forma subjacente, isto é, mesmo que não tenha clara consciência disso.

Com base em Becker (1993, 2001), existem três modelos epistemológicos que podem caracterizar o fazer pedagógico do professor: o empirista, o apriorista e o construtivista. No empirismo, a relação epistemológica se dá do objeto sobre o sujeito; no apriorismo, do sujeito sobre o objeto; e no construtivismo, há a troca entre sujeito e objeto. A seguir, tais epistemologias serão claramente explicitadas. De acordo com o autor, estas epistemologias relacionam-se à maneira como o professor entende o aluno, o que compreende por conhecimento, como concebe o processo de ensino-aprendizagem e como realiza seu trabalho. Cada epistemologia, consequentemente, implica no emprego de determinada pedagogia. Para Becker, os modelos pedagógicos são: pedagogia diretiva, não-diretiva e relacional. Analisemos estes modelos com mais detalhes. 
É preciso esclarecer que nos basearemos em Becker com o intuito de organizar as ideias e clarificá-las a respeito dos modelos epistemológicos e pedagógicos. Busca-se identificar os elementos que caracterizam cada postura epistemológica do professor e elaborar um panorama geral sobre as diferentes epistemologias, porém não se visa estabelecer rótulos. Por vezes, discordamos da maneira um tanto fechada exposta na classificação do autor. Diante disso, questiona-se: será que cada professor apoia-se em apenas um único modelo pedagógico e epistemológico? Há linhas tão claramente demarcadas ou a prática docente é mais híbrida? Estas são questões pertinentes a serem investigadas. Contudo, esse artigo preocupa-se em tecer um quadro teórico acerca das possíveis epistemologias e pedagogias do professor.

Há aulas cuja prática do professor restringe-se à mera transmissão do conteúdo, a relação professor-aluno ocorre de forma autoritária, de maneira que o professor detém o poder da fala cabendo ao aluno permanecer em silêncio. Ao desenvolver esta prática, o professor acredita em uma epistemologia, qual seja: o empirismo. Assim, tudo o que o professor decide o aluno deve executar sem provocar questionamentos e assumindo a passividade diante o processo educativo.

Segundo esta epistemologia, o indivíduo, ao nascer, não apresenta nada de conhecimento, é como uma tábula rasa, uma folha de papel em branco. O seu conhecimento será proveniente do meio físico e social. É o mundo do objeto que propicia conhecimento ao sujeito e este processo se dá por meio dos sentidos. Assim, o sujeito é determinado pelo objeto e não o contrário. Isso pode ser percebido claramente em sala de aula.

Nesta perspectiva, o professor enxerga o aluno como tábula rasa não só a partir do seu nascimento, mas toda vez que um novo conteúdo é abordado na disciplina. O mundo do objeto que determina o sujeito é representado na escola pela figura do professor. Este é o único responsável pela aprendizagem do educando, de forma que os papéis de cada um são bem definidos: o professor deve ensinar e o aluno deve aprender.

$\mathrm{O}$ empirismo associa-se diretamente à pedagogia diretiva, na qual o processo de ensino-aprendizagem pauta-se na transferência de conhecimento. Este não pode ser problematizado, uma vez que os alunos recebem os conhecimentos transmitidos pelo professor como verdades absolutas. Por conseguinte, Becker (2001, p. 19) esclarece que “ensino e aprendizagem não são pólos complementares. A própria relação é impossível. É o modelo, por excelência, do fixismo, da reprodução, da repetição".

A pedagogia diretiva baseia-se na memorização e na repetição dos conteúdos, além de auxiliar na manutenção do status quo. Isso ocorre porque a indagação e a problematização não são permitidas, pois o conhecimento do professor é inquestionável e entendido como um 
produto acabado que só pode ser reproduzido. As aulas que exigem apenas a cópia por parte dos alunos, seja do quadro ou através de um ditado, são expressão desta pedagogia.

Outra característica própria da pedagogia diretiva diz respeito à aplicação única e exclusiva da metodologia expositiva. Defende a ideia de que basta explicar bem a matéria para o conteúdo ser entendido pelos estudantes. Em geral, esse conteúdo é exposto desvinculado de seu contexto histórico. Também não se estabelecem relações entre o novo conteúdo e o conhecimento anterior do aluno. Conforme Vasconcellos (2005, p. 34), "esta metodologia de trabalho, sendo utilizado por anos seguidos, acaba deformando os educandos (e os educadores), levando à acomodação e à resistência a propostas mais inovadoras".

A pedagogia diretiva está relacionada à Educação Tradicional. Esta tem suas raízes na Antiguidade e há muito tempo domina o espaço escolar. Faz parte de uma tradição cultural que remonta os primórdios da escola, mas também se inseriu no ensino universitário. A pedagogia diretiva apoiada no empirismo tem uma forte presença no ensino básico. Isso se deve a legitimidade que adquiriu em função de seu longo histórico e a dificuldade de boa parcela da sociedade de adesão às mudanças. Muitos pais e professores, frutos de uma escola tradicional, apresentam resistência às inovações e modificações na maneira de ensinar.

Esta perspectiva vai ao encontro de um ensino de Geografia pautado na corrente da Geografia Tradicional, na qual "a primeira preocupação é descrever em lugar de explicar; inventariar e classificar em lugar de analisar e de interpretar. Esta característica é reforçada pelo enciclopedismo" (BRABANT, 1994, p. 18). Trata-se de um ensino descritivo, fragmentado e desvinculado da realidade. Dessa maneira, dificulta a possibilidade de ler criticamente o mundo e compreender o espaço geográfico, pois se reproduz uma Geografia que dissocia os aspectos naturais dos aspectos humanos.

Desenvolve-se um ensino que não se torna significativo ao aluno, visto que as abordagens geográficas não se relacionam ao cotidiano do mesmo. Mais que isso, a pedagogia diretiva e a epistemologia empirista podem corroborar para a formação de um sujeito passivo, acrítico e acomodado diante de situações problemáticas. O aluno é moldado e não desafiado, é incentivado a copiar e não a criar, é estimulado a acatar e não a questionar.

É possível traçar um paralelo entre a pedagogia diretiva e a epistemologia empirista com a concepção de educação bancária de Freire. De acordo com esta, os alunos devem receber, depositar e arquivar os conhecimentos, porém "os grandes arquivados são os homens, nesta (na melhor das hipóteses) equivocada concepção 'bancária' da educação. Arquivados, porque, fora da busca, fora da práxis, os homens não podem ser" (FREIRE, 2005, p. 66). 
Corresponde a uma visão de educação, a qual minimiza ou pode até eliminar a capacidade criativa dos alunos.

Conforme esta concepção, não se pretende desvelar a realidade, mas fazer com que esta permaneça oculta diante dos olhos da maioria. A educação bancária estimula a ingenuidade, enfatiza a permanência e caracteriza-se pela antidialogicidade. Não concebe os seres humanos como seres históricos que estão sendo, em constante devir, mas apresenta uma perspectiva de que são seres prontos, acabados. $\mathrm{O}$ mesmo vale para o conhecimento, o qual não precisa ser construído; deve ser apenas repetido, reproduzido. Será que ainda se pratica atualmente esta concepção de educação ou foi apenas uma realidade da metade do século XX quando Freire elaborou a expressão de educação bancária? Entendemos que as práticas docentes são mais complexas do que a mera reprodução de apenas uma única linha epistemológica e pedagógica. Contudo, considera-se que no contexto hodierno há ainda muitas práticas de ensino marcadas pelos pressupostos de uma educação bancária, mesmo que não exclusivamente.

Torna-se claro que nesta linha da educação (diretiva, bancária e empirista), o professor detém o saber, ao passo que os alunos nada sabem. A tarefa do aluno consiste em escutar, acatar as decisões, adaptar-se às escolhas e à maneira como o docente trabalha e acumular os conhecimentos transmitidos pelo mesmo. Por outro lado, não se pode negar que neste modelo pedagógico há um determinado controle do professor sobre a turma, o que é benéfico para o encaminhamento das atividades que se pretende realizar, desde que este controle não seja confundido com autoritarismo. Assim, empreende-se um esforço no presente artigo em não cair em dualismos para não apresentar um modelo certo e outro errado, mas sim visões de educação diferentes.

Diferenciando-se deste modelo supracitado, há uma outra epistemologia que considera que as estruturas de conhecimento já vêm programadas na bagagem hereditária do sujeito. Esta diz respeito à epistemologia apriorista. Cabe esclarecer que apriorismo provém de a piori, isto é, aquilo que vem antes, tornando-se condição para o que virá depois. Nesse caso, o que vem antes é a bagagem hereditária do aluno. Desse modo, o sujeito já nasce com conhecimento que faz parte de sua herança genética.

$\mathrm{O}$ apriorismo diferencia-se do empirismo no sentido de que o sujeito apresenta estruturas de conhecimento desde seu nascimento. O empirismo confere uma importância enorme ao exterior, ao mundo físico, de maneira que o objeto determina o sujeito, o qual é concebido como tabula rasa. No modelo apriorista a relação se inverte, pois é o sujeito que determina o objeto. A experiência não assume a centralidade do processo do conhecimento, 
mas sim o sujeito. Este é responsável pela atividade do conhecimento sem que o meio possua muita participação.

A epistemologia apriorista implica na adoção de uma pedagogia não-diretiva. $O$ processo de ensino-aprendizagem tem como foco central a figura do aluno. Isso significa que:

Uma pedagogia centrada no aluno pretende enfrentar os desmandos autoritários do modelo anterior, atribuindo ao aluno qualidades que ele não tem, como: domínio do conhecimento sistematizado em determinada área, capacidade de abstração suficiente, especialmente na área de atuação específica do professor, e volume de informações devidamente organizadas, além, é claro, do domínio das didáticas. (BECKER, 1993, p. 10)

Com base nesta epistemologia e pedagogia, o professor é um facilitador, deve apenas auxiliar o aluno. Não é o professor que assume toda a responsabilidade do processo pedagógico. Como o aluno já traz um saber de sua bagagem hereditária deve trazê-lo à consciência e complementá-lo. O papel do professor consiste em ajudá-lo neste processo, mas, para tanto, deve realizar pequenas intervenções. Logo, é o aluno que determina a ação do professor.

A não-diretividade está associada com o regime do laissez-faire, o deixar fazer. O professor deve interferir o mínimo possível, pois o aluno encontrará o caminho que irá percorrer. Nesta concepção, defende-se a ideia de que o professor não deve ensinar, pois pode não ser benéfico ao aluno. Cabe ao docente somente auxiliar na aprendizagem do aluno ao despertar o conhecimento que este já possui. A aprendizagem torna-se auto-suficiente e isso é preocupante, pois se houver algum fracasso a justificativa será a hereditariedade e não algum fator externo. Consequentemente, este déficit do aluno não poderá ser superado.

Esta postura pedagógica faz com que o aluno seja elevado a um status que não possui, assim como o professor é retirado de sua função. O aluno traz em si o saber e o papel do professor é subestimado. É preciso destacar que apesar do empirismo e apriorismo serem opostos, principalmente no que se refere à relação sujeito-objeto e professor-aluno, também se encontram semelhanças nestas duas epistemologias. O ponto em comum existente está relacionado à passividade do sujeito. Ou seja, independente se se trata do meio ou da bagagem hereditária, em ambas as situações o sujeito é predeterminado. Logo, o sujeito nada tem a fazer.

Becker (2001) também aponta que estes modelos pedagógicos e epistemológicos convergem para uma visão conservadora de educação, em que o conhecimento é algo dado, pronto e não produzido. Apresenta-se uma visão passiva do conhecimento, visto que suas condições já estão determinadas independentemente da atividade do sujeito. Tanto a 
pedagogia diretiva quanto a não-diretiva dificilmente provocam o exercício do pensar, pois se caracterizam pela reprodução.

Em contraponto às correntes anteriores, o autor apresenta uma linha teórica que defende outra perspectiva. Assenta-se na ideia de que o processo de interação entre sujeito e objeto possibilita a formação do conhecimento. Este novo olhar para o conhecimento e para o processo de ensino-aprendizagem é sustentado pela epistemologia construtivista e pela pedagogia relacional. Nenhum dos polos da relação pedagógica é hegemônico; o que ocorre é uma relação dialética entre ambos. Tanto o professor quanto o aluno possuem uma bagagem, as quais não são semelhantes e, por isso, devem entrar em relação. O desenvolvimento do conhecimento se dá pela interação, de modo que se depende da ação do sujeito e também da ação do objeto. Não é o sujeito que determina o objeto nem o objeto que determina o sujeito. Verifica-se a interação radical entre sujeito e objeto, cujo processo é ativado pelo primeiro, porém somente pode realizar-se se houver o estímulo do segundo. Portanto, o meio necessita do sujeito e este precisa da mediação do mundo do objeto.

Os conhecimentos anteriores do aluno são levados em consideração pelo professor. Nesse sentido, são os conhecimentos que o educando construiu ao longo de sua vida que possibilitarão que o mesmo continue construindo novos conhecimentos. O docente possui um saber formalizado e o discente apresenta uma história de conhecimento elaborada, a qual não deve ser desvalorizada no processo de ensino-aprendizagem. Para tanto, o professor precisa aprender o que o aluno já construiu de conhecimento, pois a partir disso será possível realizar novas aprendizagens.

Becker (2001) alerta que o construtivismo não é um método, uma prática, uma técnica de ensino ou uma forma de aprendizagem, mas trata-se de uma teoria. De acordo com o autor, é "uma teoria que nos permite interpretar o mundo em que vivemos, além de nos situar como sujeito neste mundo" (BECKER, 2001, p. 72). Então, seria essa uma teoria interessante para sustentar a prática dos professores de Geografia? Vejamos. A corrente parte do pressuposto de que o processo educativo não deve se assentar na transmissão de conhecimento, o que acarreta na mera repetição e reprodução de algo que está pronto e acabado. Ao contrário, busca-se agir e construir conhecimento a partir da realidade dos sujeitos. Dessa maneira, o conteúdo precisa ser problematizado e não aceito como verdade inquestionável.

Em um processo de aprendizagem pautado nesta perspectiva, não basta que o aluno entre em contato com o conhecimento. Mais que isso, é necessário construir e (re)descobrir os conhecimentos. Assim, será possível desenvolver uma aprendizagem significativa. O 
professor, por sua vez, possui um papel importante neste processo, visto que deve provocar desacomodações e desequilibrações no pensamento do aluno. Deve problematizar a realidade, fazendo com que o educando questione o que está posto e desenvolva sua criticidade.

Uma proposta construtivista vai ao encontro da ideia de uma educação para a cidadania e não para a reprodução do sistema vigente. Nesse sentido, Callai (2001, p. 134) assinala que deve-se romper com a mesmice da instituição educativa, "desenvolvendo uma prática que seja aberta à possibilidade de questionar o que se faz, de incorporar de fato os interesses dos alunos, e de ser capaz de produzir a capacidade de pensar, agindo com criatividade e com autoria de seu pensamento". Diferentemente das concepções epistemológicas anteriores, esta está aberta ao novo, à criação, às novas possibilidades no ensino escolar.

A pedagogia relacional, a qual está relacionada à epistemologia construtivista, entende a relação professor-aluno de outra forma comparada aos demais modelos. Isso quer dizer que o professor não toma decisões sozinho e impõe aos alunos, os quais devem aceitar passivamente. As propostas do professor são apresentadas aos alunos, os quais podem manifestar sua opinião, bem como fornecer sugestões. Trabalha-se no coletivo, em que todos podem participar. Desse modo, a relação professor-aluno é fortalecida e o mesmo também ocorre entre aluno-aluno. Salienta-se que nos três modelos pedagógicos verifica-se relação, porém em cada um ocorre de uma forma distinta dos demais.

Uma visão de aprendizagem que busca a construção do conhecimento parte do princípio de que esta tarefa não pode ser realizada pelo sujeito sozinho, mas pelo conjunto. Nesse sentido, a pedagogia relacional exige a adoção de metodologias que estejam em conformidade com esta linha teórica. A metodologia expositiva, quando sendo a única utilizada pelo docente, torna-se insuficiente nesse caso, pois corrobora para uma aprendizagem mecânica. Diante disso, Vasconcellos (2005) propõe uma metodologia na perspectiva dialética e estratégias como a exposição dialogada, o trabalho em grupo, o estudo do meio, o debate, a pesquisa e o seminário. Cabe salientar que a escolha das metodologias do educador relaciona-se à maneira como o mesmo entende seu papel, tendo em vista que "não dá para falar em metodologia separada de uma concepção de educação (e de sociedade)" (VASCONCELLOS, 2005, p. 39).

Assim como se estabeleceu uma associação entre a epistemologia empirista e a pedagogia diretiva com a concepção de educação bancária de Freire, o mesmo pode ser feito entre a epistemologia construtivista e a pedagogia relacional com a ideia de educação libertadora ou problematizadora do referido autor. Conforme Freire (1967), a educação 
problematizadora estimula a reflexão e a ação sobre a realidade, uma vez que a considera dinâmica e em permanente transformação. A dialogicidade aparece como um elemento essencial para a concretização dessa perspectiva da educação. O diálogo consiste em uma relação horizontal entre os sujeitos, possibilitando o encontro entre estes e a geração de criticidade. Trata-se de um intercâmbio de ideias que pode possibilitar o crescimento intelectual e pessoal dos envolvidos. Destarte, ultrapassa-se o modelo de educação tradicional que somente faz comunicados e deposita informações sobre os alunos de forma autoritária e baseada em uma relação vertical.

Contudo, é preciso salientar que a adoção do diálogo em sala de aula não elimina a existência de momentos explicativos e de exposição do objeto por parte do professor O que se quer enfatizar concerne à postura do professor e dos alunos, a qual deve se manter curiosa, indagadora e dialógica. Através do diálogo pretende-se desmistificar a realidade. A concepção problematizadora compreende ser necessária a inquietação e o questionamento constante do sujeito a fim de interpretar o mundo. Esta desacomodação e dúvida diante do que se apresenta na contemporaneidade permitirá uma análise crítica da realidade.

A educação libertadora, conforme a terminologia de Freire, considera a historicidade dos sujeitos, os quais são concebidos como seres inconclusos, o que evidencia a educação como um processo permanente. Ter uma clareza quanto a esta inconclusão possibilita aos sujeitos buscarem continuamente sua autonomia. Logo, a educação se faz e se refaz na práxis, pois os sujeitos não são simplesmente, mas estão sendo.

No que diz respeito ao ensino de Geografia, este deve superar sua proposta baseada na memorização e reprodução dos conteúdos se o professor estiver ancorado na epistemologia construtivista. Conforme Costella (2013, p. 65):

Construir o conhecimento geográfico é diferente de estudar Geografia de forma enciclopédica. Entender os acontecimentos refletindo sobre os fatos não significa memorizar os dados e assim apenas ter segurança em repassálos. Entender os fenômenos é conseguir, a partir deles, desenvolver a condição de mobilizar o pensamento e conseguir assim aproveitá-los em diferentes situações. Entender um fenômeno ocupando-se do outro e ser capaz de reutilizá-lo sempre que for necessário aprender o novo requer atenção e reflexão. São essas ações que permitem a construção do conhecimento.

A construção do conhecimento geográfico significa compreender o espaço geográfico considerando as múltiplas interações e processos que se desenvolvem no mesmo. Para a construção deste conhecimento, é necessário que se estabeleçam relações, de modo que os fenômenos não devem ser analisados de forma isolada. A Geografia estuda a inter-relação entre sociedade e natureza, o que exige do sujeito o entendimento desta conexão para que 
possa analisar criticamente a realidade. Ou seja, uma visão fragmentada do mundo não possibilita uma leitura crítica da realidade social, ao passo que o desenvolvimento de um processo de (re)construção do conhecimento permite a formação de um sujeito crítico e reflexivo. Pautar-se nas ideias basilares do modelo construtivista pode ser uma alternativa para tal fim.

Um professor que se apoia em uma epistemologia construtivista e uma pedagogia relacional adota uma determinada postura em sala de aula. Ou seja, ele age no sentido de propor desafios, instiga as dúvidas e os questionamentos dos alunos. Enfatiza que não existem verdades absolutas, pois o que é considerado como verdade se refere à ideia hegemônica do momento, a qual precisa ser desmistificada. Mais que isso, o professor estimula a curiosidade e a criatividade dos alunos. Parte do pressuposto de que o sentido da educação não está na cópia e repetição, mas sim na criação e reflexão dos sujeitos.

Uma prática pedagógica que esteja pautada nestes pressupostos, sob esta corrente epistemológica e pedagógica, exige uma concepção de ensinar do professor. Nesta linha de pensamento, Kaercher (2013, p. 26) se refere aos "ddd's", isto é, "uma concepção de ensinar que implica o diálogo, a dúvida, o debate, a discordância (ddd's)". Com base nesta concepção, será possível desenvolver um processo educativo que estimule o aluno a pensar, a questionar, a desenvolver seu raciocínio e elaborar seu próprio ponto de vista.

Nesta perspectiva, a Geografia possivelmente tornar-se-á uma disciplina mais interessante aos educandos, porque não terá seu objetivo centrado no acúmulo de informações sem utilidade. Os princípios que embasam o construtivismo e a pedagogia relacional contribuem para o desenvolvimento de uma Geografia Crítica na escola, uma vez que suas finalidades estão em consonância. Dessa maneira, o conhecimento geográfico possibilitará aos alunos uma leitura da realidade a partir da perspectiva espacial. Além disso, o ensino desta disciplina também será significativo ao sujeito se estiver associado à ontologia, uma vez que a Geografia é um 'pretexto para pensarmos nossa existência, uma forma de 'lerpensar' filosoficamente as coisas e as relações e influências que elas têm no nosso dia a dia, porque 'olhar as coisas' implica pensar no que os seres humanos pensam delas" (KAERCHER, 2007, p. 16). Por que não aproximar a Geografia da vida dos alunos, dos seus interesses e dos seus conflitos?

Entretanto, o modelo construtivista é de difícil concretização no espaço escolar. Há um domínio do empirismo em função de sua tradição na educação. Trata-se de uma concepção clássica que vem sendo reproduzida há alguns séculos e o fato de ser hegemônica nas instituições educativas dificulta que se provoque uma ruptura. É importante ressaltar que 
o professor tem seu fazer pedagógico amparado em determinadas concepções epistemológicas, mas, muitas vezes, não tem consciência disso. Trata-se de uma (ou mais) epistemologia(s) subjacente(s) ao trabalho docente. E mesmo que se tenha conhecimento acerca de várias concepções epistemológicas e/ou metodológicas, o professor adota diferentes estratégias de ensino, não se vinculando a uma única concepção. Enfatiza-se que para superar práticas reprodutivistas e conservadoras, não basta a crítica ao modelo pedagógico. Torna-se premente que seja realizada também uma crítica epistemológica. Para tanto, é preciso formar professores pesquisadores e reflexivos.

\section{POR UM PROFESSOR PESQUISADOR E REFLEXIVO}

Para pensar na formação de um professor pesquisador torna-se interessante lançar o questionamento apresentado por Bachelard (1996, p. 12), qual seja: “criar - e sobretudo manter - um interesse vital pela pesquisa desinteressada não é o primeiro dever do educador, em qualquer estágio de formação?”. Uma docência que não seja marcada pela pesquisa caracteriza-se pela reprodução mecânica de conhecimentos elaborados por outros.

A pesquisa do professor é fundamental não somente por engajar-se na construção do conhecimento no que diz respeito à sua disciplina, mas também no que concerne a uma outra questão. Trata-se de conhecer como se procedem os processos de aprendizagem, ou seja, como o aluno aprende. O professor precisa aprender a aprender para que possa ensinar (COSTELLA, 2012). Isto é, o ensinar e o aprender devem estar articulados, de forma que ao entender como o aluno aprende, o professor poderá estruturar a maneira como irá ensinar. Por isso, a pesquisa acerca de processos de conhecimento é essencial na formação docente.

Ao mesmo tempo, não se pode desconsiderar a realidade concreta em que vive a grande maioria dos professores, os quais possuem uma carga horária excessiva. Assim, há questões que ultrapassam sua vontade, pois, por mais que se interessem pela pesquisa, chega um momento em que se deparam com a falta de tempo para executar tal atividade. Como um professor com 60 horas irá desenvolver uma pesquisa? Mas como fazer para mudar esta situação? Sabe-se da necessidade de políticas públicas que garantam maior valorização ao professor e que lhe possibilite desenvolver um trabalho de qualidade. Da mesma forma que não se pretende culpar o professor, também não se pode fugir de suas responsabilidades.

No que se refere à noção de professor reflexivo, elaborada por Donald Schon, esta começa a se destacar no Brasil a partir dos anos de 1990. Contrapõe-se à concepção do professor na racionalidade técnica, uma vez que valoriza os saberes dos professores e os 
considera como sujeitos capazes de produzir conhecimento. A relevância de formar um professor reflexivo consiste no fato de que a revisão e o repensar de suas ações permitem a transformação das mesmas. O docente que reflete sobre sua prática passa a enxergá-la com um outro olhar, o que possibilitará o estabelecimento de uma nova prática. Diante disso, o que se afirma:

[...] é a necessidade da reflexão sobre a prática a partir da apropriação de teorias como marco para as melhorias das práticas de ensino, em que o professor é ajudado a compreender o seu próprio pensamento e a refletir de modo crítico sobre sua prática e, também, a aprimorar seu modo de agir, seu saber-fazer, internalizando também novos instrumentos de ação. (LIBÂNEO, 2012, P. 83)

Para refletir acerca da prática, é preciso questioná-la. Ou seja, a reflexão pressupõe o questionar e o autoquestionar-se. Para tanto, é necessário algo que desperte esta problematicidade (GHEDIN, 2012). Se não houver indagação e incerteza, não há o porquê se refletir. Logo, pode-se afirmar que as noções de professor pesquisador e professor reflexivo estão imbricadas, são complementares. Para se tornar um professor reflexivo deve-se, antes de tudo, ser um professor pesquisador. Ressalta-se a importância de se formar um professor reflexivo, pois cabe perguntar: como se formarão alunos reflexivos se não houver professores reflexivos? Como é possível um professor tornar-se reflexivo?

Cabe esclarecer que formar professores pesquisadores e reflexivos é importante não somente para conhecer os processos de aprendizagem e para refletir sobre suas práticas. Para além disso, é fundamental para que desenvolvam o exercício de pôr em questão suas concepções epistemológicas. Isto é, a crítica epistemológica pressupõe que os professores sejam pesquisadores e reflexivos. Nesta condição torna-se possível o ato de (re)pensar as opções epistemológicas que orientam as práticas educativas.

\section{CONSIDERAÇÕES FINAIS}

É digno de nota que a problemática com a qual se está analisando não se refere a um problema prático, unicamente, mas diz respeito a uma questão epistemológica. Ou seja, a preocupação está nos pressupostos que possibilitam a formação de um bom profissional docente. Assim, torna-se premente repensar os cursos de formação de professores, visto que as concepções epistemológicas e pedagógicas do educador fundamentam a sua prática.

Refletir acerca do ensino e, em especial, do ensino de Geografia na contemporaneidade implica uma discussão concernente à formação docente realizada nas 
universidades. Trata-se de uma discussão de caráter epistemológico, tendo em vista a necessidade premente de trazer à tona questionamentos e incertezas que a tradição acadêmica tende a ocultar. Isto é, o paradigma da ciência moderna hegemônico na universidade tem sido capaz de lidar com as demandas hodiernas? Quais as concepções de Educação e de Geografia predominantes nos cursos de licenciatura em Geografia? Como formar professores reflexivos, visto que os próprios professores formadores tiveram sua formação assentada no paradigma técnico-intrumental?

Portanto, salienta-se que o debate referente ao ensino de Geografia escolar deve estar atrelado à formação inicial do professor de Geografia. Esse debate requer um aprofundamento teórico, de maneira que não recaia em discursos meramente técnicos e metodológicos. Ir às raízes do fazer docente torna-se essencial, pois nossas escolhas epistemológicas influenciarão a ação educativa. Logo, é preciso resgatar o sentimento de incerteza a fim de propiciar indagações que remetam à reflexão sobre nossas concepções, nossa visão de mundo, de ciência e de ensino. A partir disso, será possível propor alternativas de fato coerentes com o ideal de escola e universidade que buscamos alcançar.

\section{REFERÊNCIAS}

BACHELARD, G. A formação do espírito científico: contribuição para uma psicanálise do conhecimento. Rio de Janeiro: Contraponto, 1996.

BECKER, F. A epistemologia do professor: o cotidiano da escola. 10. Ed. Petrópolis, RJ: Vozes, 1993.

BECKER, F. Educação e construção do conhecimento. Porto Alegre: Artmed Editora, 2001.

BRABANT, J-M. Crise da Geografia, Crise da Escola. In: OLIVEIRA, A. U. (Org.) Para onde vai o ensino de geografia? São Paulo: Contexto, 1994.

CALLAI, H. C.. A geografia e a escola: muda a geografia? Muda o ensino? In: Revista Terra Livre, n. 16. (p. 133-152). São Paulo, 2001.

COSTELLA, R. Z. Escola: espaço de responsabilidade social. Revista Trajetória Multicursos - Edição Especial XVI Fórum Internacional de Educação, Osório, ano 3, n. 7, ago. 2012.

COSTELLA, R. Z. Movimentos para (não) dar aulas de Geografia e sim capacitar o aluno para diferentes leituras. In: CASTROGIOVANNI, A. C.; TONINI, I. M.; KAERCHER, N. A. (Orgs.). Movimentos no ensinar geografia. Porto Alegre: Imprensa Livre: Compasso LugarCultura, 2013.

FREIRE, P. Educação como prática de liberdade. Rio de Janeiro: Paz e Terra, 1967.

FREIRE, P. Pedagogia do Oprimido. Rio de Janeiro: Paz e Terra, 2005.

GHEDIN, E. Professor reflexivo: da alienação da técnica à autonomia da crítica. In:

PIMENTA, S. G.; GHEDIN, E. (Orgs.). Professor reflexivo no Brasil: gênese e crítica de um conceito. 7. Ed. São Paulo: Cortez, 2012. 
KAERCHER, N. A. Práticas pedagógicas para lerpensar o mundo, converentendersar com o outro e entenderscobrir a si mesmo. In: REGO, N.; CASTROGIOVANNI, A. C.;

KAERCHER, N. A. (Orgs). Geografia: práticas pedagógicas para o ensino médio. Porto Alegre: Artmed, 2007.

KAERCHER, N. A. Os movimentos que meus mestres me ensinam: ddd's, signos, alimentos, escadas, luzes, grenais. In: CASTROGIOVANNI, A. C.; TONINI, I. M..; KAERCHER, N. A. (Orgs.). Movimentos no ensinar geografia. Porto Alegre: Imprensa Livre: Compasso LugarCultura, 2013.

KAERCHER, N. A.. Se a geografia escolar é um pastel de vento o gato come a geografia crítica. Porto Alegre: Evangraf, 2014.

LIBÂNEO, J. C.. Reflexividade e formação de professores: outra oscilação do pensamento pedagógico brasileiro? In: PIMENTA, S. G.; GHEDIN, E. (Orgs.). Professor reflexivo no Brasil: gênese e crítica de um conceito. 7. Ed. São Paulo: Cortez, 2012.

VASCONCELLOS, C. S. Construção do conhecimento em sala de aula. São Paulo: Libertad, 2005.

VEIGA-NETO, A. É preciso ir aos porões. Revista Brasileira de Educação, v. 17, n. 50, p. 267-282, maio-ago. 2012.

Recebido em junho de 2016.

Aceito em junho de 2017. 